\title{
RESPEITO, PROMOÇÃO E PROTEÇÃO DOS DIREITOS DAS PESSOAS LGBTQIAP+ NAS RELAÇÕES DE TRABALHO
}

\section{RESPECT, PROMOTION AND PROTECTION OF THE RIGHTS OF LGBTQIAP+ PEOPLE IN WORK RELATIONS}

\author{
Renata Moura Miranda de Oliveira*
}

\begin{abstract}
RESUMO: Este artigo tem como objetivo principal analisar a realidade de discriminação, desrespeito, negação e sistemática violação de direitos humanos por que passam as pessoas LGBTQIAP+, nas mais diversas relações sociais, os reflexos dessa realidade na empregabilidade dessas pessoas, a responsabilidade social e jurídica das empresas com a garantia de condições justas e favoráveis de trabalho a essa minoria e o papel fundamental do Ministério Público do Trabalho na promoção da igualdade de oportunidades e no combate à discriminação no trabalho em face das pessoas LGBTQIAP+. O método utilizado na pesquisa foi a revisão de literatura.
\end{abstract}

PALAVRAS CHAVES: discriminação; emprego; Ministério Público do Trabalho; pessoas LGBTQIAP+;

ABSTRACT: The main objective of this article is to analyze the reality of discrimination, disrespect, refuse and systematic violation of human rights experienced by LGBTQIAP+ people, in the most several social relations, the reflections of this reality in the employability of these people. As well as social and legal responsibility of companies with the guarantee of fair and favorable working conditions for this minority and the fundamental role of the Labour Prosecution Service (MPT) in promoting equal opportunities and combating discrimination at work in the face of LGBTQIAP + people. The method used in the research was the literature review.

KEYWORDS: discrimination; employment; Labour Prosecution Service (MPT), LGBTQIAP+.

\section{INTRODUÇÃO}

Neste breve artigo, discorrer-se-á sobre a realidade de discriminação, desrespeito, negação e sistemática violação de direitos humanos por que passam as pessoas LGBTQIAP+, nas mais diversas relações sociais, os reflexos dessa realidade na empregabilidade dessas pessoas, a responsabilidade social e jurídica das empresas com a garantia de condições justas e favoráveis de trabalho a essa minoria e o papel fundamental do Ministério Público do Trabalho na promoção da igualdade

\footnotetext{
* Bacharela em Direito pela Universidade Federal da Bahia.
} 
de oportunidades e no combate à discriminação no trabalho em face desse grupo vulnerável.

Inicialmente, serão feitas considerações sobre o direito à igualdade e o direito à não discriminação. Na sequência, far-se-á uma análise sucinta sobre a proteção internacional, constitucional e infraconstitucional dos direitos humanos e liberdades fundamentais das pessoas LGBTQIAP+. Em seguida, abordar-se-á a sistemática violação de direitos humanos e liberdades fundamentais dessas pessoas e a repetição desse padrão de conduta nas relações de trabalho.

Falar-se, também, sobre os mecanismos de suplantação do cenário de opressão e exclusão vivenciado por essas pessoas em situação de inequívoca desvantagem, inserindo-se, nesse contexto, a responsabilidade das empresas, no Estado Democrático de Direito, com o respeito, promoção e proteção dos direitos das pessoas que compõem esse grupo vulnerável.

Derradeiramente, comentar-se-á sobre o papel do Ministério Público do Trabalho na promoção da igualdade de oportunidades e no combate à discriminação no trabalho em face das pessoas LGBTQIAP+.

\section{CONSIDERAÇÕES SOBRE O DIREITO À IGUALDADE E O DIREITO À NÃO DISCRIMINAÇÃO}

Discriminação é conceituada por Maurício Godinho Delgado como qualquer conduta, fundada em critério injustamente desqualificante, que nega à pessoa tratamento compatível com o padrão jurídico assentado para a situação por ela vivenciada, impedindo-lhe, assim, o acesso equitativo às oportunidades existentes. (DELGADO, 2016, p.885)

A Convenção Interamericana Contra Toda Forma de Discriminação e Intolerância, em seu art. $1^{\circ}$, conceitua discriminação como:

[...] qualquer distinção, exclusão, restrição ou preferência, em qualquer área da vida pública ou privada, cujo propósito ou efeito seja anular ou restringir o reconhecimento, gozo ou exercício, em condições de igualdade, de um ou mais direitos humanos e liberdades fundamentais consagrados nos instrumentos internacionais aplicáveis aos Estados 
Partes. (RODRIGUES JR., 2019, p. 689).

De outro turno, a Convenção 111 da OIT conceitua a discriminação nas relações de trabalho como:

[...] toda distinção, exclusão ou preferência fundada na raça, cor, sexo, religião, opinião política, ascendência nacional ou origem social, que tenha por efeito destruir ou alterar a igualdade de oportunidades ou de tratamento em matéria de emprego ou profissão (art. 1,a)".(BRASIL, Decreto 62.150, 1968)

Tomando-se como referência os precitados conceitos, infere-se que discriminação, em qualquer área da vida, implica reprovável negação ao princípio da igualdade.

O direito à igualdade e o direito à não discriminação são direitos humanos consagrados, expressamente, na Carta das Nações Unidas, na Declaração Universal dos Direitos Humanos e em diversos instrumentos internacionais de direitos humanos: Pacto Internacional de Direitos Civis e Políticos (BRASIL, Decreto 592, 1992), Pacto Internacional de Direitos Econômicos, Sociais e Culturais - (BRASIL, Decreto 591, 1992), Convenção Americana de Direitos Humanos (BRASIL, Decreto 678, 1992), Protocolo San Salvador (BRASIL, Decreto 3.321, 1999), Proclamação de Teerã, Convenções 100 (BRASIL, Decreto 41.721, 1957) e 111 (BRASIL, Decreto 62.150, 1968), da OIT, Declaração Sociolaboral do Mercosul.

As palavras de pórtico da Declaração Universal dos Direitos Humanos (DUDH) não deixam dúvidas quanto à extrema relevância da igualdade no cenário internacional de proteção dos direitos humanos, ao estatuir que "todos os seres humanos nascem livres e iguais em dignidade e direitos" (art. $1^{\circ}$, DUDH).

$\mathrm{O}$ art. VII, por sua vez, reforça o princípio da igualdade e, ao mesmo tempo, estabelece a proteção contra a discriminação, ao proclamar:

Todos são iguais perante a lei e têm direito, sem qualquer distinção, a igual proteção da lei. Todos têm direito a igual proteção contra qualquer discriminação que viole a presente Declaração e contra qualquer incitamento a tal discriminação. (RODRIGUES JR., 2019, p. 92).

No Brasil, a Constituição de 1988, nesta mesma linha protetiva e combativa, 
instituiu, como objetivos fundamentais da República Federativa do Brasil, a construção de uma sociedade livre, justa e solidária, na qual se promove o bem de todos, sem preconceitos de origem, raça, cor, sexo, idade e quaisquer outras formas de discriminação (art. $3^{\circ}$, I e IV), confirmando, em diversos dispositivos, a consagração do direito ineliminável à igualdade e o repúdio à discriminação atentória aos direitos e liberdades fundamentais (arts. $5^{\circ}$, caput, e incisos I, XLI, XLII; $7^{\circ}, \mathrm{XXX}, \mathrm{XXXI}, \mathrm{XXXII).}$

A legislação infraconstitucional pátria, igualmente, ampara os referidos direitos, fazendo-os incidir, inclusive, nas relações laborais - consoante se depreende, dentre outros, dos arts. $3^{\circ}$, parágrafo único, $5^{\circ}$ e 461 , todos da CLT, bem como do art. $1^{\circ}$, da Lei 9029/95 - em decorrência da eficácia horizontal/diagonal direta e imediata dos direitos fundamentais nas relações privadas, adveniente de sua dimensão objetiva.

\section{PROTEÇÃO INTERNACIONAL, CONSTITUCIONAL E INFRACONSTITUCIONAL DOS DIREITOS HUMANOS E LIBERDADES FUNDAMENTAIS DAS PESSOAS LGBTQIAP+}

No que concerne, especificamente, às pessoas lésbicas, gays, bissexuais, travestis, transgêneros, queer, intersexo, assexuais ou pan/poli (LGBTQIAP+), amparam-nas, no âmbito internacional, além dos supramencionados diplomas normativos, os Princípios de Yogyakarta de 2006 (Complementados pelo YP mais 10 em 2017), que versam sobre a aplicação da legislação internacional de direitos humanos em relação à orientação sexual e identidade de gênero.

No preâmbulo do documento que veicula os princípios de Yogyakarta, lê-se que

Orientação sexual" refere-se à capacidade de cada pessoa de experimentar uma profunda atração emocional, afetiva ou sexual por indivíduos de gênero diferente, do mesmo gênero ou de mais de um gênero, assim como de ter relações íntimas e sexuais com essas pessoas; já "identidade de gênero" alude à experiência interna, individual e profundamente sentida que cada pessoa tem em relação ao gênero, que pode, ou não, corresponder ao sexo atribuído no nascimento, incluindo-se aí o sentimento pessoal do corpo (que pode envolver, por livre escolha, modificação da aparência ou função corporal por meios médicos, cirúrgicos ou outros) e outras expressões de gênero, inclusive o modo de vestir-se, o modo de falar $e$ 
maneirismos. (DHNET.ORG, 2019).

À luz das estatuições contidas nos Princípios de Yogyakarta, a orientação sexual e identidade de gênero autodefinidas por cada pessoa "constituem parte essencial de sua personalidade e um dos aspectos mais básicos de sua autodeterminação, dignidade e liberdade" (Princípio 3). Já o Princípio 12, relativo ao direito ao trabalho, enuncia que "toda pessoa tem o direito ao trabalho digno e produtivo, a condições de trabalho justas e favoráveis e à proteção contra o desemprego, sem discriminação por motivo de orientação sexual ou identidade de gênero".

Ainda no cenário internacional, podem ser citadas a Convenção Interamericana Contra toda Forma de Discriminação e Intolerância, a Opinião Consultiva $n^{\circ} 24$, da Corte Interamericana de Direitos Humanos, e a Resolução 17/19, do Conselho de Direitos Humanos da ONU, as quais, além de expressarem forte preocupação em relação a atos de violência e discriminação, em todas as regiões do mundo, cometidos contra as pessoas por causa de sua orientação sexual e identidade de gênero, carregam diretrizes e princípios que amparam a proteção das pessoas LGBTQIAP+.

Confira-se, a propósito, trecho da supracitada Opinião Consultiva $n^{\circ} 24$, da Corte Interamericana de Direitos Humanos:

O reconhecimento da identidade de gênero encontra-se ligada necessariamente à ideia segundo a qual o sexo e o gênero devem ser percebidos como parte de uma construção identitária que resulta da decisão livre e autônoma de cada pessoa,sem que se deve estar sujeita à sua genitália. Dessa forma,o sexo, assim como as identidades, as funções e os atributos construídos socialmente que se atribuem a diferenças biológicas em todo o sexo assinalado ao nascer, longe de constituir-se em componentes objetivos e imutáveis do estado civil que individualiza uma pessoa, por ser um fato da natureza física ou biológica, terminam sendo traços que dependem da apreciação subjetiva de quem o detenha ou residam em construção da identidade de gênero autopercebida relacionada com olivre desenvolvimento da personalidade, a autodeterminação sexual e o direito a vida privada.(...)o Estado deve assegurar que os indivíduos de todas as orientações sexuais e identidades de gênero possam viver com a mesma dignidade e o mesmo respeito que têm todas as pessoas. (https://www.corteidh.or.cr, 2020)

Adite-se, também, que o Comitê de Direitos Econômicos, Sociais e Culturais, 
vinculado ao Pacto Internacional de Direitos Econômicos, Sociais e Culturais (PIDESC), seguindo uma linha interpretativa progressista e histórico-evolutiva, explicitou que o sentido e alcance da expressão "outra situação", constante do art. $2^{\circ}$, item 2 (BRASIL, Decreto 591, 1992), do mencionado diploma, inclui a orientação sexual, o que reforça o aparato internacional de proteção aos direitos humanos e liberdades fundamentais das pessoas LGBTQIAP+.

No Brasil, além dos textos legislativos gerais, constitucionais e infraconstitucionais, que enaltecem o princípio da igualdade e vedam condutas discriminatórias de quaisquer ordem, pode-se mencionar, de forma específica, 0 Decreto $n^{\circ} 8.727 / 2016$, que dispõe sobre o uso do nome social e o reconhecimento da identidade de gênero de pessoas travestis e transexuais, no âmbito da administração pública federal, direta, autárquica e fundacional. Mencione-se, outrossim, a Resolução n. ${ }^{0} 12 / 2015$ do Conselho Nacional de Combate à Discriminação e Promoção dos Direitos de Lésbicas, Gays, Bissexuais, Travestis e Transexuais

No que tangencia ao papel da jurisprudência do Supremo Tribunal Federal (STF) na reafirmação e consolidação dos direitos das pessoas LGBTQIAP+, registrese que a Suprema Corte, por unanimidade de votos, julgou procedente a ADPF $\mathrm{n}^{\circ} 132$ e a ADI $n^{\circ} 4.277$, com eficácia erga omnes e efeito vinculante, para dar ao art. 1723 do Código Civil interpretação conforme à Constituição, para dele excluir qualquer significado que impeça o reconhecimento da união contínua, pública e duradoura de pessoas do mesmo sexo como entidade familiar.

Pontue-se, ainda, que no RE 845.779 foi reconhecida repercussão geral ao tema (778) "Possibilidade de uma pessoa, considerados os direitos da personalidade e a dignidade da pessoa humana, ser tratada socialmente como se pertencesse a sexo diverso do qual se identifica e se apresenta publicamente".

Para o Ministro Luís Roberto Barroso, relator do supramencionado Recurso Extraordinário, do ponto de vista jurídico, há, pelo menos, três fundamentos que justificam conferir aos transexuais o direito de serem tratados socialmente de acordo com a sua identidade de gênero, inclusive na utilização de banheiros de acesso público: Dignidade como valor intrínseco: o direito à igualdade; Dignidade como 
autonomia: o direito de ser quem se é; Princípio democrático e proteção às minorias (STF, RE 845.779, 2015).

Em compasso com a referida temática, pode-se mencionar Portaria, editada pela Procuradoria Geral do Trabalho, a Portaria PGT n. 1036, de 1/12/15, que assegurou a todas as pessoas travestis e transexuais, assim como a todas aquelas cuja identificação civil não reflita adequadamente sua identidade de gênero, o uso do nome social no âmbito do MPT, bem como garantiu o uso de banheiros, vestiários e demais espaços segregados por gênero, quando houver, de acordo com o nome social e a identidade de gênero de cada pessoa.

Registre-se, ainda, que no julgamento da ADI 4275, o STF atribuiu interpretação conforme à Constituição Federal e o Pacto de San Jose de Costa Rica ao art. 58 da Lei 6.015/1973, de modo a reconhecer aos trangêneros, independentemente da cirurgia de transgenitalização ou da realização de tratamentos hormonais ou patologizantes, o direito à substituição de prenome e sexo diretamente no registro civil.

Sob o viés repressivo, o plenário do STF, por maioria, em decisão igualmente digna de encômios, aprovou a tese, a qual, dentre outros pontos, estabeleceu que, até que o Congresso Nacional edite leis específicas, as condutas homofóbicas e transfóbicas, reais ou supostas, se enquadram nos crimes previstos na Lei 7.716/89 (STF, ADO n²6, 2019).

\section{A SISTEMÁTICA VIOLAÇÃO DE DIREITOS HUMANOS E LIBERDADES FUNDAMENTAIS DAS PESSOAS LGBTQIAP+}

Inobstante tal aparato normativo nacional e internacional, somado ao avanço da jurisprudência brasileira no papel de proteção e promoção dos direitos humanos e liberdades fundamentais das pessoas LGBTQIAP+, assiste-se, diuturnamente, a violações aos princípios da igualdade e da não discriminação, que são, lamentavelmente, exponenciadas, nesse grupo vulnerável e em inequívoca desvantagem. Frequentemente, seus direitos são ultrajados, com menoscabo completo às suas dignidades. 
$\mathrm{Na}$ introdução aos Princípios de Yogyakarta consta que violações de direitos humanos que atingem pessoas por causa de sua orientação sexual ou identidade de gênero, lamentavelmente, constituem um padrão global e consolidado. O rol dessas violações inclui "execuções extrajudiciais, tortura e maus-tratos, agressões sexuais e estupro, invasão de privacidade, detenção arbitrária, negação de oportunidades de emprego e educação e sérias discriminações em relação ao gozo de outros direitos humanos"(DHNET.ORG, 2019).

No Brasil, além das multicitadas violações, foram contabilizadas, a partir de denúncias de assassinato, registradas, entre 2011 e 2018, pelo Disque 100 (um canal criado para receber informações sobre violações aos direitos humanos), pelo Transgender Europe e pelo GGB (Grupo Gay da Bahia), 4.422 mortes no período, o que equivale a 552 mortes por ano, ou uma vítima de homofobia a cada 16 horas no país. (NOTÍCIAS UOL, 2019).

Estigmas, estereótipos e preconceitos, enraizados na sociedade, fatalmente, deságuam em comportamentos e práticas discriminatórias, diretas (explícitas) ou indiretas (aparentemente neutras, mas que resultam em impacto desproporcional sobre grupos em desvantagem), em direção a essas pessoas. Soma-se, ainda, ao fato de que, comumente, a discriminação relacionada à orientação sexual e identidade de gênero tem interseções com outras formas de discriminação, advenientes, por exemplo, da raça, cor, idade, posição socioeconômica, deficiência, o que faz emergir a discriminação múltipla (overlapping oppression) contra essas pessoas.

\section{PADRÃO DE CONDUTA DISCRIMINATÓRIA EM DIREÇÃO ÀS PESSOAS LGBTQIAP+ NAS RELAÇÕES DE TRABALHO.}

No mundo do trabalho, esse padrão de conduta discriminatória se reproduz, seja na fase pré-contratual (quando pessoas LGBTQIAP+ não são contratadas simplemente em decorrência da orientação sexual ou identidade de gênero), seja no curso da relação de trabalho (quando essas pessoas são duramente discriminadas no ambiente de trabalho, sendo vítimas de assédio moral, pelo só fato de serem quem são e, muitas vezes, são dispensados, aparentemente, sem justa causa, quando, em 
verdade, se percebe, na prática, que tais dispensas decorrem de preconceitos velados), ou mesmo na fase pós-contratual (quando os empregadores fazem propagar informações desabonadoras à conduta de tais pessoas).

Sabe-se que para a contratação, ascensão ou permanência na empresa da pessoa humana trabalhadora, independentemente de suas características, peculiaridades, orientações sexuais, identidades ou expressões de gênero, está o empregador, em regra, obrigado a observar o princípio da neutralidade, em consonância com o qual somente as habilidades técnicas exigidas para o exercício do função podem ser levadas em consideração. É inadmissível, portanto, considerar a orientação sexual ou identidade de gênero como um fator de discrímen juridicamente legítimo.

\section{SUPLANTAÇÃO DO CENÁRIO DE OPRESSÃO E EXCLUSÃO VIVENCIADO PELAS PESSOAS LGBTQIAP+.}

A superação desse cenário de desrespeito e intolerância para com as pessoas LGBTQIAP+ perpassa, inexoravelmente, pela suplantação da injustiça que essas pessoas amargam, uma injustiça que, muitas vezes, não tem natureza legal, ou econômica, mas é predominantemente simbólica e cultural, adveniente de modelos sociais que insistem em excluir os grupos "outsideres" ( STF, RE 845.779, 2015).

A suplantação deste trágico panorama de opressão e exclusão exige a concretização máxima do princípio da igualdade, em seu sentido formal (na lei e perante a lei) e material (distribuição equitativa de riquezas e bem estar social), mas também da ampliação do seu sentido, para abarcar, também, a igualdade como reconhecimento, que significa o respeito às minorias, suas identidades, seus direitos, suas diferenças, sejam elas quais forem ( STF, RE 845.779,2015).

Nancy Fraser, citada pelo Ministro Luís Roberto Barroso, no voto oral proferido no RE 845.779, aponta que o caminho para remediar esse quadro generalizado de exclusão envolve uma transformação cultural capaz de criar um mundo aberto à diferença ('difference-friendly world'), onde a assimilação aos padrões culturais da maioria não seja o preço a ser pago pelo mútuo respeito. O Ministro rememora, ainda, 
as percucientes lições de Boaventura Souza Santos, para quem "as pessoas têm o direitos de ser iguais quando a diferença os inferioriza, e o direito a ser diferentes quando a igualdade os descaracteriza".

No cenário internacional, vale mencionar o projeto "livres \& iguais" do alto comissariado das nações unidas para direitos humanos (acnudh), implementado em parceria com a fundação purpose, e que tem por objetivo a suplantação desse cenário de opressão e exclusão vivenciado pelas pessoas LGBTQIAP+, especialmente a partir da conscientização sobre a violência e a discriminação homofóbica e transfóbica e da promoção de um maior respeito pelos direitos dessas pessoas, em todos os lugares do mundo (NACOESUNIDAS.ORG, 2019).

\section{A RESPONSABILIDADE SOCIAL E JURÍDICA DAS EMPRESAS NO RESPEITO, PROMOÇÃO E PROTEÇÃO DOS DIREITOS HUMANOS E LIBERDADES FUNDAMENTAIS DAS PESSOAS LGBTQIAP+.}

Como corolário da função social (arts. $5^{\circ}$, XXIII, e 170, caput, CRFB; 421 e $\left.1228, \S 1^{\circ}, \mathrm{CC}\right)$ que as empresas estão obrigadas a cumprir, entende-se estarem elas jungidas ao dever de respeitar, proteger e promover os direitos humanos e liberdades fundamentais de todas as pessoas, inclusive das que integram o grupo LGBTQIAP+, promovendo uma cultura empresarial de igualdade e diversidade que englobe o respeito aos direitos dessas pessoas. Indubitavelmente, promover a diversidade e o pluralismo, no contexto laboral, exponencia a potencialidade de alcance de desenvolvimento pleno e de exercício efetivo da cidadania.

No cumprimento de sua inafastável função social, incumbe às empresas, ainda, assegurar, por exemplo, a todas as pessoas travestis e transexuais, ou todas aquelas cuja identificação civil não reflita adequadamente sua identidade de gênero, o uso do nome social no âmbito da empresa, garantindo, ainda, a utilização de uniformes, banheiros, vestiários e demais espaços segregados por gênero, de acordo com o nome social e a identidade de gênero de cada pessoa.

Impõe-se, além disso, que os empregadores, por si, ou por seus prepostos, abstenham-se de praticar, fomentar ou aceitar qualquer ato de vilipêndio à dignidade 
da pessoa LGBTQIAP+. Exige-se, neste passo, que as empresas adotem uma postura instransigente contra o preconceito, o desrespeito e a intolerância, protegendo, incansavelmente, as escolhas existenciais de todas as pessoas inseridas na engrenagem empresarial. Incumbe-lhe, enfim, garantir que grupos vulneráveis, como o são o das pessoas LGBTQIAP+, sejam resguardados da tirania da maioria e tenham seus direitos fundamentais inarredavelmente observados.

É responsabilidade da empresa respeitar os direitos humanos e fundamentais de todxs, na esteira do quanto disposto na Declaração Tripartite de Princípios sobre Empresas Multinacionais e Política Social e nos Princípios Orientadores da Nações Unidas sobre Empresas e Direitos Humanos (Princípios de Ruggie), destacando-se o Princípio 12, que estabelece:

a responsabilidade das empresas de respeitar os direitos humanos refere-se aos direitos humanos internacionalmente reconhecidos que incluem, no mínimo, os direitos enunciados na Carta Internacional de Direitos Humanos e os princípios relativos aos direitos fundamentais estabelecidos na Declaração da Organização Internacional do Trabalho relativa aos princípios e direitos fundamentais no trabalho. (RODRIGUES JR., 2019, p.148 )

Dessume-se do Princípio 12 de Ruggie que as empresas, além de estarem obrigadas a observar os os direitos enunciados na Carta Internacional de Direitos Humanos, devem obediência incondicional, no mínimo, aos princípios relativos aos direitos fundamentais estabelecidos na Declaração da Organização Internacional do Trabalho relativa aos princípios e direitos fundamentais no trabalho, dentre os quais está a eliminação da discriminação em matéria de emprego e ocupação (art. 2, "d").

Neste sentido, dispõe, também, o art. $4^{\circ}$ da Declaração Sociolaboral do Mercosul:

todo trabalhador tem garantida a igualdade efetiva de direitos, tratamento e oportunidades no emprego e ocupação, sem distinção ou exclusão por motivo de raça, origem nacional, cor, sexo ou orientação sexual, idade, credo, opinião política ou sindical, ideologia, posição econômica ou qualquer outra condição social ou familiar, em conformidade com as disposições legais vigentes. (RODRIGUES JR., 2019, p.485 ) 
Ademais, com o desiderato de incorporar sua responsabilidade de respeitar os direitos humanos, as empresas estão atreladas ao compromisso de expressar essa responsabilidade, através de:

\begin{abstract}
uma declaração política que: A.Seja aprovada no mais alto nível de direção da empresa; B.Baseie-se em assessoria especializada interna e/ou externa; C. Estabeleça o que a empresa espera, em relação aos direitos humanos, de seu pessoal, seus sócios e outras partes diretamente vinculadas com suas operações, pro dutos ou serviços; D. Seja publicada e difundida interna e externamente a todo o pessoal, aos parceiros comerciais e outras partes interessadas; E. Seja refletida nas políticas e procedimentos operacionais necessários para incorporar o compromisso assumido no âmbito de toda a empresa" (Princípio 16 de Ruggie). (RODRIGUES JR., 2019, p.148)
\end{abstract}

No Brasil, foi publicado, em 2018, o Decreto $n^{\circ}$ 9.571, que estabelece as Diretrizes Nacionais sobre Empresas e Direitos Humanos, para médias e grandes empresas, incluídas as empresas multinacionais com atividades no país, com clara inspiração nos Princípios de Ruggie. O art. $8^{\circ}$, IX, do premencionado Decreto, enuncia que:

Caberá às empresas combater a discriminação nas relações de trabalho e promover a valorização e o respeito da diversidade em suas áreas e hierarquias, com ênfase em: IX - respeitar a livre orientação sexual, a identidade de gênero e a igualdade de direitos da população de lésbicas, gays, bissexuais, travestis, transexuais ou transgêneros em âmbito empresarial. (BRASIL, Decreto nº 9.571, 2018).

A bandeira da livre iniciativa (art. $1^{\circ}$, IV, CRFB) não pode servir de escudo para negação da dignidade da pessoa humana (art. $1^{\circ}$, III, CRFB) - atributo indissociável da pessoa LGBTQIAP+ - e para a não promoção do valor social do trabalho (arts. $1^{\circ}$, IV e 170, III, CRFB), tampouco para suprimir o núcleo ineliminável do direito fundamental social ao trabalho (art. $\left.6^{\circ}, \mathrm{CRFB}\right)$ e, por consectário, violar o limite dos limites.

Admitir condutas empresariais dissonantes com todo este arcabouço normativo implica desconsiderar a força normativa dos princípios, estabelecidos na Constituição Federal, e nos diplomas internacionais de direitos humanos. Resulta, ainda, em negação à máxima efetividade dos direitos fundamentais, desvalorização da 
dignidade humana, sob a perspectiva da autonomia para fazer escolhas existenciais, além de completo desprezo à busca legítima por felicidade que não pode ser subtraída de nenhum ser humano.

\section{O PAPEL DO MINISTÉRIO PÚBLICO DO TRABALHO NA PROMOÇÃO DA IGUALDADE DE OPORTUNIDADES E NO COMBATE À DISCRIMINAÇÃO EM FACE DAS PESSOAS LGBTQIAP+}

O combate à discriminação das pessoas LGBTQIAP+, nos ambientes de trabalho, insere-se na atuação prioritária do Ministério Público do Trabalho, mormente por intermédio da Coordenadoria Nacional de Promoção da Igualdade de Oportunidades e Eliminação da Discriminação no Trabalho - Coordigualdade.

Membros do Ministério Público do Trabalho têm atuado, incansavelmente, na promoção da qualificação e efetiva inclusão das pessoas LGBTQIAP+, nos ambientes de trabalho, assegurando-lhes igualdade de oportunidades e, também, combatendo as mais diversas formas de discriminação a que estão sujeitas essas pessoas no universo laboral.

O Ministério Público do Trabalho, especialmente através da Coordigualdade, tem se destacado, também, na distribuição de cartilha sobre o tema, na promoção de audiências públicas, palestras e conferências, com o desiderato de conscientizar a população em geral e, especialmente, as empresas quanto ao papel fundamental que têm de inclusão, respeito e valorização das pessoas LGBTQIAP+.

Registre-se, inclusive, que, em ação conjunta do Ministério Público do Trabalho (MPT), da Organização Internacional do Trabalho (OIT) e da Fundação José Silveira, têm sido promovidas ações de capacitação e empregabilidade de Pessoas Trans, através do projeto denominado "Cozinha \& Voz - Empregabilidade Trans", idealizado para empoderamento e formação de pessoas trans para o cargo de assistente de cozinha com conteúdo desenvolvido pela voluntária no Projeto, a chef Paola Carosella.

No viés repressivo de atuação, quando não é aceita a solução consensual do conflito, com expedição de recomendação (art. 6 XX, LC 75/93), ou assinatura de 
Termo de Ajuste de Conduta (art. $5^{\circ}, \S 6^{\circ}$, da Lei 7347/85), o Ministério Público do Trabalho tem ajuizado ações civis públicas, com pleitos ressarcitórios, inclusive de condenação por dano moral coletivo, e inibitórios, com obrigações de fazer e não fazer e, até mesmo, pedidos de reintegração/indenização em dobro, em situações de dispensas discriminatórias.

Mencione-se, também, a Portaria PGT (Procuradoria Geral do Trabalho) 1220/2018, que instituiu a Política Nacional de Equidade de Gênero, Raça e diversidade, estabelecendo princípios, diretrizes e ações que favoreçam, assegurem e promovam a equidade de gênero, raça e diversidade de todas as pessoas no âmbito da instituição.

\section{CONCLUSÃO}

As palavras de pórtico da Declaração Universal dos Direitos Humanos (DUDH) não deixam dúvidas quanto à extrema relevância da igualdade, no cenário internacional de proteção dos direitos humanos, ao estatuir que "todos os seres humanos nascem livres e iguais em dignidade e direitos" (art. $1^{\circ}$, DUDH).

No Brasil, a Constituição de 1988, nesta mesma linha protetiva e combativa, instituiu, como objetivos fundamentais da República Federativa do Brasil, a construção de uma sociedade livre, justa e solidária, na qual se promove o bem de todos, sem preconceitos de origem, raça, cor, sexo, idade e quaisquer outras formas de discriminação (art. $3^{\circ}$, I e IV), confirmando, em diversos dispositivos, a consagração do direito ineliminável à igualdade e o repúdio à discriminação atentória aos direitos e liberdades fundamentais (arts. $5^{\circ}$, caput, e incisos I, XLI, XLII; $7^{\circ}, \mathrm{XXX}, \mathrm{XXXI}, \mathrm{XXXII)}$.

A construção de uma sociedade fraterna, pluralista e sem preconceitos, fundada na harmonia social (Preâmbulo da Constituição de 1988), pressupõe, necessariamente, o enfrentamento e o combate da realidade de discriminação, desrespeito, negação e sistemática violação de direitos humanos por que passam as pessoas LGBTQIAP+, nas mais diversas relações sociais, inclusive nos ambientes de trabalho.

Inobstante tal aparato normativo nacional e internacional, somado ao avanço 
da jurisprudência brasileira no papel de proteção e promoção dos direitos humanos e liberdades fundamentais das pessoas LGBTQIAP+, assiste-se, diuturnamente, a violações aos princípios da igualdade e da não discriminação, que são, lamentavelmente, exponenciadas, nesse grupo vulnerável e em inequívoca desvantagem. Frequentemente, seus direitos são ultrajados, com menoscabo completo às suas dignidades.

A promoção do bem de todos, sem preconceitos de origem, raça, sexo, cor, idade e quaisquer outras formas de discriminação (art. $3^{\circ}$, IV, CRFB/1988) perpassa, dentre outras medidas, pela responsabilidade social e jurídica das empresas com a garantia de condições justas e favoráveis de trabalho a essa minoria.

Neste desiderato, tem se destacado o papel fundamental do Ministério Público do Trabalho na promoção da igualdade de oportunidades e no combate à discriminação no trabalho em face desse grupo em desvantagem.

Afinal, admitir condutas empresariais dissonantes com todo este arcabouço normativo implica desconsiderar a força normativa dos princípios, estabelecidos na Constituição Federal, e nos diplomas internacionais de direitos humanos. Resulta, ainda, em negação à máxima efetividade dos direitos fundamentais, desvalorização da dignidade humana, sob a perspectiva da autonomia para fazer escolhas existenciais, além de completo desprezo à busca legítima por felicidade que não pode ser subtraída de nenhum ser humano.

\section{REFERÊNCIAS}

BRASIL.

ADO $\quad \mathrm{n}^{\circ}$

26.

Disponível

em $<$ http://portal.stf.jus.br/processos/detalhe.asp?incidente=4515053>. Acesso em 15 de novembro de 2019.

BRASIL. Decreto $\mathrm{n}^{\circ} 3.321$, de 30 de dezembro de 1999. Promulga o Protocolo Adicional à Convenção Americana sobre Direitos Humanos em Matéria de Direitos Econômicos, Sociais e Culturais "Protocolo de São Salvador", concluído em 17 de novembro de 1988, em São Salvador, El Salvador. Brasília, DF, dezembro 1999. Disponível em <http://www.planalto.gov.br/ccivil_03/decreto/D3321.htm>. Acesso em 28 de novembro de 2019.

BRASIL. Decreto $n^{\circ}$ 591, de 6 de julho de 1992. Pacto Internacional sobre Direitos 
Econômicos, Sociais e Culturais. Promulgação. Brasília, DF, julho 1992. Disponível em <http://www.planalto.gov.br/ccivil_03/decreto/1990-1994/d0591.htm>. Acesso em 28 de novembro de 2019.

BRASIL. Decreto $\mathrm{n}^{\circ}$ 592, de 6 de julho de 1992. Atos Internacionais. Pacto Internacional sobre Direitos Civis e Políticos. Promulgação. Brasília, DF, julho 1992. Disponível em <http://www.planalto.gov.br/ccivil_03/decreto/1990-1994/d0592.htm>. Acesso em 28 de novembro de 2019.

BRASIL. Decreto $\mathbf{n}^{\mathbf{0}} \mathbf{6 2 . 1 5 0}$, de 19 de janeiro de 1968. Disponível em <http://www.planalto.gov.br/ccivil_03/decreto/1950-1969/d62150.htm>. Acesso em 16 de janeiro de 2020.

BRASIL. Decreto $\mathbf{n}^{\mathbf{0}}$ 9.571, de 21 de novembro de 2018. Disponível em <http://www.planalto.gov.br/ccivil_03/_ato2015-2018/2018/decreto/D9571.htm>. Acesso em 16 de janeiro de $202 \overline{0}$.

BRASIL. RE 845.779. Disponível em <https://www.conjur.com.br/dl/transexuais-re845779-voto-barroso.pdf>. Acesso em 15 de novembro de 2019.

BRASIL. CONVENÇÃO AMERICANA SOBRE DIREITOS HUMANOS. Disponível em $<$ https://www.cidh.oas.org/basicos/portugues/c.convencao_americana.htm>. Acesso em 28 de novembro de 2019.

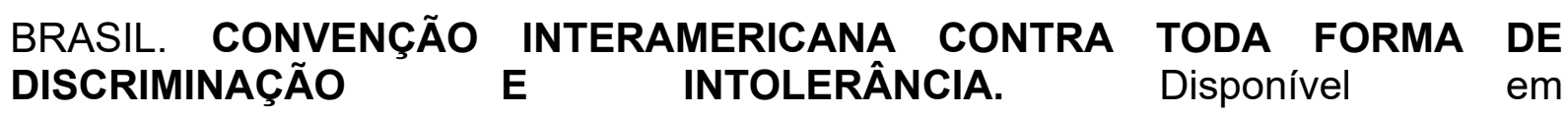
$<$ https://www.oas.org/en/sla/dil/docs/inter_american_treaties_A-

69_Convencao_Interamericana_disciminacao_intolerancia_POR.pdf>. Acesso em 16 de janeiro de 2020 .

BRASIL. DECLARAÇÃO SOCIOLABORAL DO MERCOSUL. Disponível em http://www.dhnet.org.br/direitos/deconu/a_pdf/dec_sociolaboral_mercosul.pdf.

Acesso em 11 de dezembro de 2019.

DECLARAÇÃO UNIVERSAL DOS DIREITOS HUMANOS. Disponível em $<$ https://nacoesunidas.org/wp-content/uploads/2018/10/DUDH.pdf>. Acesso em 27 de novembro de 2019.

DELGADO, Maurício Godinho. Curso de Direito do Trabalho. 15. ed. São Paulo: LTr, 2016.

GUIA DE ACESSO A DIREITOS E SERVIÇOS PARA PESSOAS TRANS. https://mpt.mp.br/pgt/publicacoes/cartilhas/cartilha-paginas-trans/@@displayfile/arquivo_pdf. Acesso em: 11 de dezembro de 2019.

LIVRES \& IGUAIS. Disponível em https://nacoesunidas.org/campanha/livreseiguais/. 
Acesso em: 28 de novembro de 2019.

OPINIÃO CONSULTIVA $\mathbf{N}^{\circ} \mathbf{2 4}$, CORTE INTERAMERICANA DE DIREITOS HUMANOS. DISPONÍVEL EM https://www.corteidh.or.cr, Acesso em: 04 de novembro de 2020.

PORTAL UOL. Brasil registra uma morte por homofobia a cada 16 horas, aponta relatório. Disponível em <https://noticias.uol.com.br/cotidiano/ultimasnoticias/2019/02/20/brasil-matou-8-mil-lgbt-desde-1963-governo-dificulta-divulgacaode-dados.htm>. Acesso em: 15 de novembro de 2019.

PRINCÍPIOS DE YOGYAKARTA. Princípios sobre a aplicação da legislação internacional de direitos humanos em relação à orientação sexual e identidade de gênero. Disponível em http://www.dhnet.org.br/direitos/sos/gays/principios_de_yogyakarta.pdf. Acesso em: 15 de novembro de 2019.

RODRIGUES JR, Edson Beas. Convenções da OIT e outros Instrumentos de Direito Internacional Público e Privado relevantes ao Direito do Trabalho. 4 ed. ampl. São Paulo: LTR, 2019.

TRATAMENTO SOCIAL A SER DISPENSADO A TRANSEXUAIS. Anotações Para 0 Voto Oral Do Ministro Luís Roberto Barroso. Disponível em https://www.conjur.com.br/dl/transexuais-re-845779-voto-barroso.pdf . Acesso em: 15 de novembro de 2019. 